\title{
Association of polymorphisms of THBS2 and HSPA8 with hypertension in Japanese individuals with chronic kidney disease
}

\author{
MITSUTOSHI OGURI ${ }^{1}$, KIMIHIKO KATO ${ }^{2}$, KIYOSHI YOKOI ${ }^{2}$, SACHIRO WATANABE $^{3}$, NORIFUMI METOKI ${ }^{4}$, \\ HIDEMI YOSHIDA ${ }^{5}$, KEI SATOH ${ }^{5}$, YUKITOSHI AOYAGI ${ }^{6}$, YUTAKA NISHIGAKI ${ }^{6}$, \\ HIDEYO YOSHIDA $^{7}$, YOSHINORI NOZAWA ${ }^{8}$ and YOSHIJI YAMADA ${ }^{9}$
}

\begin{abstract}
${ }^{1}$ Department of Cardiology, Japanese Red Cross Nagoya First Hospital, Nagoya; ${ }^{2}$ Department of Cardiovascular Medicine, Gifu Prefectural Tajimi Hospital, Tajimi; ${ }^{3}$ Department of Cardiology, Gifu Prefectural General Medical Center, Gifu; ${ }^{4}$ Department of Internal Medicine, Hirosaki Stroke Center; ${ }^{5}$ Department of Vascular Biology, Institute of Brain Science, Hirosaki University Graduate School of Medicine, Hirosaki; ${ }^{6}$ Department of Genomics for Longevity and Health and

${ }^{7}$ Research Team for Promoting Independence of the Elderly, Tokyo Metropolitan Institute of Gerontology, Tokyo; ${ }^{8}$ Gifu International Institute of Biotechnology, Kakamigahara; ${ }^{9}$ Department of Human Functional Genomics, Life Science Research Center, Mie University, Tsu, Japan
\end{abstract}

Received October 14, 2008; Accepted December 9, 2008

DOI: $10.3892 / \mathrm{mmr} 00000085$

\begin{abstract}
The purpose of the present study was to identify gene polymorphisms that confer susceptibility to hypertension in individuals with chronic kidney disease (CKD), thereby contributing to the prediction of genetic risk for this condition. The study population comprised 1824 Japanese individuals with CKD [estimated glomerular filtration rate (eGFR) $<60 \mathrm{ml}$ $\min ^{-1} 1.73 \mathrm{~m}^{-2}$, including 1257 subjects with hypertension and 567 controls. The genotypes for 50 polymorphisms of 46 candidate genes were determined using a method that combines the polymerase chain reaction and sequence-specific oligonucleotide probes with suspension array technology. An initial screen of allele frequencies by the $\chi^{2}$ test revealed that two polymorphisms were significantly (false discovery rate $<0.05$ ) associated with the prevalence of hypertension in individuals with CKD. Subsequent multivariable logistic regression analysis with adjustment for age, gender and the prevalence of diabetes mellitus revealed that these two polymorphisms, 3949T $\rightarrow \mathrm{G}$ (3'-UTR) of the thrombospondin 2 gene (THBS2; odds ratio in recessive model, 8.31) and $-110 \mathrm{~A} \rightarrow \mathrm{C}$ of the heat shock $70-\mathrm{kDa}$ protein 8 gene (HSPA8; odds ratio in recessive model, 0.72$)$ were significantly $(\mathrm{P}<0.05)$ associated with the prevalence of hypertension. The variant $G$ allele
\end{abstract}

Correspondence to: Dr Yoshiji Yamada, Department of Human Functional Genomics, Life Science Research Center, Mie University, 1577 Kurima-machiya, Tsu, Mie 514-8507, Japan

E-mail: yamada@gene.mie-u.ac.jp

Key words: polymorphism, genetics, hypertension, chronic kidney disease of $T H B S 2$ was a risk factor for hypertension, whereas the variant $C$ allele of $H S P A 8$ was protective against this condition. A stepwise forward selection procedure also demonstrated that the THBS2 and HSPA8 genotypes were significant $(\mathrm{P}<0.05)$ and independent determinants of hypertension. Determination of genotypes for these polymorphisms may prove informative for the prediction of genetic risk for hypertension in Japanese individuals with CKD. Validation of these findings will require additional studies with independent subject panels.

\section{Introduction}

Individuals with chronic kidney disease (CKD) frequently suffer from hypertension, which is sometimes intractable, making it difficult to achieve the target blood pressure (1-3). Hypertension in patients with CKD is an independent predictor of both the progression of CKD and the development of cardiovascular disease (3-7). Strict control of blood pressure is thus highly desirable in such patients and is thought to delay the progression of renal injury (8). The identification of genetic markers for hypertension and subsequent personalized intervention at an early stage of CKD may prove effective in reducing the prevalence of cardiovascular disease. However, genetic factors underlying predisposition to hypertension in individuals with CKD have remained largely uncharacterized. Furthermore, given ethnic differences in lifestyle and environmental factors, as well as in genetic background and renal function, it is important to examine genetic variants related to hypertension in individuals with CKD in each ethnic group.

In the present study, we performed an association study for 50 candidate gene polymorphisms and hypertension in 1824 Japanese individuals with CKD. The purpose of the study was to identify genetic variants that confer susceptibility to hypertension in individuals with $\mathrm{CKD}$, thereby providing a basis for the personalized prevention of this condition. 
Table I. Primers, probes and additional polymerase chain reaction conditions for the genotyping of polymorphisms associated with hypertension in individuals with chronic kidney disease.

\begin{tabular}{|c|c|c|c|c|c|c|}
\hline Gene & Polymorphism & & Primers & Probes & $\begin{array}{l}\text { Annealing } \\
\text { temp. }\left({ }^{\circ} \mathrm{C}\right)\end{array}$ & Cycles \\
\hline \multirow[t]{2}{*}{ THBS2 } & $3949 \mathrm{~T} \rightarrow \mathrm{G}$ & Sense & AACCCAAGTGCCTTCAGAGGAT & Probe 1 GATGTTCATCTCTGAGTTCCA & 60 & 50 \\
\hline & (3'-UTR) & Antisense & CTCCACATAAAGTCTCATATATCAC & Probe 2 GATGTTCATCTCTGCGTTCCA & & \\
\hline \multirow[t]{2}{*}{ HSPA8 } & $-110 \mathrm{~A} \rightarrow \mathrm{C}$ & Sense & CAGGGGGCGGCATTCTGGC & Probe 1 GAATATTCCAGGGTTTTCGCCT & 60 & 50 \\
\hline & & Antisense & CTTCTGGGCCAATCACCGAG & Probe 2 ACGGGAGGCGAAACCCCTG & & \\
\hline
\end{tabular}

\section{Materials and methods}

Study population. The study population comprised 1824 unrelated Japanese individuals (1120 males, 704 females) with CKD who visited the outpatient clinics of or were admitted to one of the participating hospitals: Gifu Prefectural General Medical Center and Gifu Prefectural Tajimi Hospital (Gifu Prefecture, Japan), and Hirosaki University Hospital, Reimeikyo Rehabilitation Hospital and Hirosaki Stroke Center (Aomori Prefecture, Japan) between October 2002 and March 2008 due to various symptoms or for an annual health checkup. Also included were individuals recruited to a population-based prospective cohort study of aging and agerelated diseases in Gunma Prefecture and Tokyo, Japan.

Estimated glomerular filtration rate (eGFR) was calculated using the simplified prediction equation proposed by the Japanese Society of Nephrology and based on that described in the Modification of Diet in Renal Disease (MDRD) Study: eGFR $\left(\mathrm{ml} \mathrm{min}{ }^{-1} 1.73 \mathrm{~m}^{-2}\right)=194 \mathrm{x}$ [age (years) $]^{-0.287} \mathrm{x}$ [serum creatinine (mg/dl) $]^{-1.094}$ [x 0.739 if female]. The National Kidney Foundation-Kidney Disease Outcomes Quality Initiative guidelines recommend a diagnosis of CKD if eGFR is $<60 \mathrm{ml} \mathrm{min}{ }^{-1}$ $1.73 \mathrm{~m}^{-2}$ (9). Non-linear relations between GFR and the risk of adverse outcomes, such as death, cardiovascular events and hospitalization, have been demonstrated, with increased risk being associated with an eGFR $<60 \mathrm{ml} \mathrm{min}^{-1} 1.73 \mathrm{~m}^{-2}$ and markedly increased risk with values falling below $45 \mathrm{ml} \mathrm{min}^{-1}$ $1.73 \mathrm{~m}^{-2}$ (3). Therefore, the criterion of an eGFR $<60 \mathrm{ml} \mathrm{min}{ }^{-1}$ $1.73 \mathrm{~m}^{-2}$ was adopted for the diagnosis of CKD in the present study.

The 1257 subjects (789 males, 468 females) with hypertension had a systolic blood pressure $\geq 160 \mathrm{mmHg}$ and/or a diastolic blood pressure $\geq 95 \mathrm{mmHg}$ prior to medical treatment. Individuals with valvular heart disease, congenital malformations of the heart or vessels, or renal or endocrinologic diseases that cause secondary hypertension were excluded from the study. The control subjects comprised 567 individuals (331 males, 236 females) who visited the out-patient clinics of the participating hospitals for an annual health checkup or were community-dwelling individuals in the prospective cohort study with normal blood pressure (systolic blood pressure $<140 \mathrm{mmHg}$ and diastolic blood pressure $<90 \mathrm{mmHg}$ ) and no history of hypertension or of taking antihypertensive medication. The hypertensive and control individuals had or did not have diabetes mellitus, hypercholesterolemia or obesity.
Blood pressure was measured at least twice, with subjects resting in a sitting position for $>5$ min prior to measurement. Measurements were taken by a skilled physician according to the guidelines of the American Heart Association (10). The study protocol complied with the Declaration of Helsinki and was approved by the Committees on the Ethics of Human Research of Mie University Graduate School of Medicine, Hirosaki University Graduate School of Medicine, Gifu International Institute of Biotechnology, Tokyo Metropolitan Institute of Gerontology, and participating hospitals. Written informed consent was obtained from each participant.

Selection and genotyping of polymorphisms. With the use of public databases, including PubMed (NCBI) and Online Mendelian Inheritance in Man (NCBI), we selected 46 candidate genes that have been characterized and proposed to be associated with hypertension. On the basis of published studies or by searching PubMed and single nucleotide polymorphism (SNP) databases [dbSNP (NCBI) and Japanese SNP (JSNP)], we further selected 50 polymorphisms of these genes, most of which were located in the promoter region or exons, that might be expected to result in changes in the function or expression of the encoded protein (data not shown). Wild-type and variant alleles of the polymorphisms were determined from the original sources.

Venous blood $(7 \mathrm{ml})$ was collected in tubes containing $50 \mathrm{mmol} / \mathrm{l}$ EDTA (disodium salt), and genomic DNA was isolated using a kit (Genomix; Talent, Trieste, Italy). Genotypes of the 50 polymorphisms were determined at G\&G Science (Fukushima, Japan) by a method that combines the polymerase chain reaction and sequence-specific oligonucleotide probes with suspension array technology (Luminex, Austin, TX). Primers, probes and other conditions for the genotyping of polymorphisms significantly associated with CKD are shown in Table I. Detailed genotyping methodology was as previously described (11).

Statistical analysis. Quantitative data were compared between subjects with hypertension and the controls by the unpaired Student's t-test. Categorical data were compared by the $\chi^{2}$ test. Allele frequencies were estimated by the gene counting method, and the $\chi^{2}$ test was used to identify departure from Hardy-Weinberg equilibrium. In an initial screening, allele frequencies $(2 \times 2)$ of each polymorphism from subjects with hypertension and controls were compared using the $\chi^{2}$ test. Given the multiple comparisons of genotypes, the false 
Table II. Characteristics of subjects with hypertension and controls among individuals with chronic kidney disease.

\begin{tabular}{|c|c|c|c|}
\hline Characteristic & Hypertension & Controls & P-value \\
\hline No. of subjects & 1257 & 567 & \\
\hline Age (years) & $71.0 \pm 8.7$ & $70.6 \pm 9.3$ & 0.4219 \\
\hline Gender (male/female, \%) & $62.8 / 37.2$ & $58.4 / 41.6$ & 0.0753 \\
\hline Body mass index $\left(\mathrm{kg} / \mathrm{m}^{2}\right)$ & $23.5 \pm 3.4$ & $23.3 \pm 3.3$ & 0.1572 \\
\hline Current or former smoker $(\%)$ & 20.5 & 23.6 & 0.1414 \\
\hline Systolic blood pressure $(\mathrm{mmHg})$ & $154 \pm 26$ & $128 \pm 17$ & $<0.0001$ \\
\hline Diastolic blood pressure (mmHg) & $82 \pm 15$ & $73 \pm 12$ & $<0.0001$ \\
\hline Hypercholesterolemia (\%) & 31.0 & 28.0 & 0.2088 \\
\hline Serum total cholesterol $(\mathrm{mmol} / \mathrm{l})$ & $5.22 \pm 1.02$ & $5.23 \pm 1.00$ & 0.8676 \\
\hline Serum triglyceride $(\mathrm{mmol} / \mathrm{l})$ & $1.70 \pm 1.09$ & $1.57 \pm 0.94$ & 0.0194 \\
\hline Serum HDL-cholesterol (mmol/l) & $1.32 \pm 0.42$ & $1.4 \pm 0.40$ & 0.0001 \\
\hline Diabetes mellitus (\%) & 41.2 & 21.0 & $<0.0001$ \\
\hline Fasting plasma glucose $(\mathrm{mmol} / \mathrm{l})$ & $7.10 \pm 3.10$ & $6.69 \pm 2.91$ & 0.0247 \\
\hline Glycosylated hemoglobin (\%) & $6.01 \pm 1.52$ & $5.65 \pm 1.37$ & 0.0008 \\
\hline Serum creatinine $(\mu \mathrm{mol} / \mathrm{l})$ & $119.8 \pm 135.8$ & $91.7 \pm 26.2$ & $<0.0001$ \\
\hline eGFR $\left(\mathrm{ml} \mathrm{min}{ }^{-1} 1.73 \mathrm{~m}^{-2}\right)$ & $47.4 \pm 11.8$ & $51.0 \pm 8.0$ & $<0.0001$ \\
\hline End-stage renal disease $(\%)$ & 3.6 & 0.4 & $<0.0001$ \\
\hline
\end{tabular}

Quantitative data are the means \pm SD. Smoker, smoking $\geq 10$ cigarettes daily. Hypercholesterolemia, serum total cholesterol $\geq 5.72 \mathrm{mmol} / 1(220 \mathrm{mg} / \mathrm{dl})$ or taking lipid-lowering medication. Diabetes mellitus, fasting plasma glucose $\geq 6.93 \mathrm{mmol} / \mathrm{l}(126 \mathrm{mg} / \mathrm{dl}$ ), glycosylated hemoglobin (hemoglobin A1c) content $\geq 6.5 \%$, or taking antidiabetes medication.

discovery rate (FDR) was calculated (12) from the distribution of P-values for allele frequencies of the 50 polymorphisms. Polymorphisms with an FDR $<0.05$ were further examined by multivariable logistic regression analysis with adjustment for covariates. Multivariate logistic regression analysis was thus performed with hypertension as a dependent variable and with independent variables including age, gender ( 0 , female; 1 , male), the prevalence of diabetes mellitus ( 0 , no history of the condition; 1, positive history), and the genotype of each polymorphism. The P-value, odds ratio and $95 \%$ confidence interval were calculated. Each genotype was assessed according to dominant $(0$, wild-type homozygote; 1 , heterozygote $=$ variant homozygote $)$, recessive $(0$, wild-type homozygote $=$ heterozygote; 1 , variant homozygote $)$, and additive $[(0,0)$ wild-type homozygote; $(1,0)$, heterozygote; $(0,1)$, variant homozygote] genetic models. Additive models included the additive 1 model (heterozygotes versus wild-type homozygotes) and the additive 2 model (variant homozygotes versus wild-type homozygotes), which were analyzed simultaneously using a single statistical model. We also performed a stepwise forward selection procedure to examine the effects of genotypes as well as of other covariates on hypertension. The $\mathrm{P}$-value levels for inclusion in and exclusion from the model were 0.25 and 0.1 , respectively. In the stepwise forward selection procedure, each genotype was examined according to a dominant or recessive model on the basis of statistical significance in the multivariable logistic regression analysis. With the exception of the initial screening by the $\chi^{2}$ test (FDR <0.05), a P-value <0.05 was considered statistically significant. Statistical significance was examined by twosided tests performed with JMP version 5.1 software and JMP Genomics version 3.2 software (SAS Institute, Cary, NC).

\section{Results}

The characteristics of the 1824 study subjects are shown in Table II. In the subjects with hypertension, the prevalence of diabetes mellitus and end-stage renal disease, the serum concentrations of triglyceride and creatinine, the fasting plasma glucose concentration, the blood glycosylated hemoglobin content, as well as systolic and diastolic blood pressure were greater than in the controls, whereas the serum concentration of high density lipoprotein (HDL)-cholesterol and eGFR were lower than in the controls.

Evaluation of allele frequencies by the $\chi^{2}$ test revealed that 14 polymorphisms were related ( $\mathrm{P}$-value for allele frequency $<0.05)$ to the prevalence of hypertension. Of these, 3949T $\rightarrow \mathrm{G}$ (3'-UTR) of the thrombospondin 2 gene (THBS2) and $-110 \mathrm{~A} \rightarrow \mathrm{C}$ of the heat shock 70-kDa protein 8 gene (HSPA8) were significantly associated with the prevalence of hypertension on the basis of an FDR for allele frequency $<0.05$ (Table III). The genotype distributions for all 14 polymorphisms related to hypertension are also shown in Table III. Those for the two polymorphisms significantly associated with this condition were in Hardy-Weinberg equilibrium in both hypertensive and control subjects (Table IV).

Multivariate logistic regression analysis with adjustment for age, gender and the prevalence of diabetes mellitus revealed that the $3949 \mathrm{~T} \rightarrow \mathrm{G}$ (3'-UTR) polymorphism (rs8089) of THBS2 (dominant, recessive and additive 2 models) and the $-110 \mathrm{~A} \rightarrow \mathrm{C}$ polymorphism (rs 1008438) of HSPA8 (dominant, recessive and additive 2 models) were significantly $(\mathrm{P}<0.05)$ associated with hypertension (Table V). The variant $G$ allele of THBS2 was a risk factor for hypertension, whereas the variant $C$ allele of HSPA8 was protective against this condition. 
Table III. Genotype distributions of polymorphisms related (P-value for allele frequency <0.05) to hypertension among individuals with chronic kidney disease as determined by the $\chi^{2}$ test.

\begin{tabular}{|c|c|c|c|c|c|c|}
\hline Gene symbol & Polymorphism & $\mathrm{dbSNP}$ & Hypertension & Controls & P-value & FDR \\
\hline \multirow[t]{4}{*}{ THBS2 } & 3949T $\rightarrow$ G $(3$ '-UTR $)$ & rs8089 & & & 0.0012 & 0.048 \\
\hline & $T T$ & & $1011(80.4)$ & $487(85.9)$ & & \\
\hline & $T G$ & & $227(18.1)$ & $79(13.9)$ & & \\
\hline & $G G$ & & $19(1.5)$ & $1 \quad(0.2)$ & & \\
\hline \multirow[t]{4}{*}{ HSPA8 } & $-110 \mathrm{~A} \rightarrow \mathrm{C}$ & rs 1008438 & & & 0.0028 & 0.048 \\
\hline & $A A$ & & $432(34.4)$ & $165(29.1)$ & & \\
\hline & $A C$ & & $584(46.5)$ & $263(46.4)$ & & \\
\hline & $C C$ & & $241(19.2)$ & $139(24.5)$ & & \\
\hline \multirow[t]{4}{*}{$G C K$} & $-30 \mathrm{G} \rightarrow \mathrm{A}$ & rs1799884 & & & 0.0052 & 0.065 \\
\hline & $G G$ & & $877(69.8)$ & $366(64.6)$ & & \\
\hline & $G A$ & & $348(27.7)$ & $173(30.5)$ & & \\
\hline & $A A$ & & 32 (2.6) & $28 \quad(4.9)$ & & \\
\hline \multirow[t]{4}{*}{ APOC 3} & $-482 \mathrm{C} \rightarrow \mathrm{T}$ & rs2854117 & & & 0.0102 & 0.102 \\
\hline & $C C$ & & $337(26.8)$ & $192(33.9)$ & & \\
\hline & $C T$ & & $634(50.4)$ & $258(45.5)$ & & \\
\hline & $T T$ & & $286(22.8)$ & $117(20.6)$ & & \\
\hline \multirow[t]{4}{*}{ GHSR } & $\mathrm{A} \rightarrow \mathrm{G}$ & rs509035 & & & 0.0127 & 0.106 \\
\hline & $A A$ & & $216(17.2)$ & $87(15.4)$ & & \\
\hline & $A G$ & & $609(48.5)$ & $246(43.5)$ & & \\
\hline & $G G$ & & $430(34.3)$ & $233(41.2)$ & & \\
\hline \multirow[t]{4}{*}{$I L 1 B$} & $-511 \mathrm{C} \rightarrow \mathrm{T}$ & rs16944 & & & 0.0152 & 0.108 \\
\hline & $C C$ & & $362(28.8)$ & $196(34.6)$ & & \\
\hline & $C T$ & & $606(48.2)$ & $257(45.3)$ & & \\
\hline & $T T$ & & $289(23.0)$ & $114(20.1)$ & & \\
\hline \multirow[t]{4}{*}{$M M P 3$} & $\mathrm{~A} \rightarrow \mathrm{G}($ Lys45Glu $)$ & rs679620 & & & 0.0259 & 0.138 \\
\hline & $A A$ & & $143(11.4)$ & $75(13.2)$ & & \\
\hline & $A G$ & & $524(41.7)$ & $258(45.5)$ & & \\
\hline & $G G$ & & $590(46.9)$ & $234(41.3)$ & & \\
\hline \multirow[t]{4}{*}{ FBN1 } & $1875 \mathrm{~T} \rightarrow \mathrm{C}$ & rs 25458 & & & 0.0316 & 0.138 \\
\hline & $T T$ & & $388(30.9)$ & $194(34.2)$ & & \\
\hline & $T C$ & & $609(48.5)$ & $280(49.4)$ & & \\
\hline & $C C$ & & $260(20.7)$ & $93(16.4)$ & & \\
\hline \multirow[t]{4}{*}{$A L O X 5 A P$} & $162 \mathrm{~A} \rightarrow \mathrm{C}$ & rs4769055 & & & 0.0321 & 0.138 \\
\hline & $A A$ & & $321(25.6)$ & $124(21.9)$ & & \\
\hline & $A C$ & & $634(50.5)$ & $285(50.3)$ & & \\
\hline & $C C$ & & 300 (23.9) & $158(27.9)$ & & \\
\hline \multirow[t]{4}{*}{ PTGIS } & $1117 \mathrm{C} \rightarrow \mathrm{A}$ & rs5629 & & & 0.0350 & 0.138 \\
\hline & $C C$ & & $764(60.8)$ & $313(55.2)$ & & \\
\hline & $C A$ & & $436(34.7)$ & $224(39.5)$ & & \\
\hline & $A A$ & & $57 \quad(4.5)$ & $30 \quad(5.3)$ & & \\
\hline \multirow[t]{4}{*}{ GCLC } & $-129 \mathrm{C} \rightarrow \mathrm{T}$ & rs17883901 & & & 0.0391 & 0.138 \\
\hline & $\mathrm{CC}$ & & $957(76.1)$ & 406 (71.6) & & \\
\hline & $\mathrm{CT}$ & & $284(22.6)$ & $151(26.6)$ & & \\
\hline & $\mathrm{TT}$ & & $16(1.3)$ & $10 \quad(1.8)$ & & \\
\hline
\end{tabular}


Table III. Continued.

\begin{tabular}{|c|c|c|c|c|c|c|}
\hline Gene symbol & Polymorphism & $\mathrm{dbSNP}$ & Hypertension & Controls & P-value & FDR \\
\hline \multirow[t]{4}{*}{ OR13G1 } & $\mathrm{A} \rightarrow \mathrm{G}($ Ile132Val) & rs1151640 & & & 0.0420 & 0.138 \\
\hline & $A A$ & & $174(13.9)$ & $67(11.8)$ & & \\
\hline & $A G$ & & $592(47.2)$ & $251(44.3)$ & & \\
\hline & $G G$ & & $489(39.0)$ & $249(43.9)$ & & \\
\hline \multirow[t]{4}{*}{$M M P 1$} & $-1607 / 1 \mathrm{G} \rightarrow 2 \mathrm{G}$ & rs 1799750 & & & 0.0434 & 0.138 \\
\hline & $1 G l G$ & & $135(10.7)$ & $80(14.1)$ & & \\
\hline & $1 G 2 G$ & & $566(45.0)$ & $256(45.2)$ & & \\
\hline & $2 G 2 G$ & & $556(44.2)$ & $231(40.7)$ & & \\
\hline \multirow[t]{4}{*}{$F 7$} & $11496 \mathrm{G} \rightarrow \mathrm{A}(\mathrm{Arg} 353 \mathrm{Gln})$ & rs6046 & & & 0.0466 & 0.138 \\
\hline & $G G$ & & $1119(89.0)$ & $487(85.9)$ & & \\
\hline & $G A$ & & $133(10.6)$ & $76(13.4)$ & & \\
\hline & $A A$ & & $5 \quad(0.4)$ & $4 \quad(0.7)$ & & \\
\hline
\end{tabular}

Numbers in parentheses are percentages.

Table IV. Hardy-Weinberg P-values for subjects with hypertension and controls.

\begin{tabular}{lccc}
\hline Gene & Polymorphism & Hypertension & Controls \\
\hline THBS2 & 3949T $\rightarrow \mathrm{G}(\text { 3'-UTR })^{\prime}$ & 0.1322 & 0.2307 \\
HSPA8 & $-110 \mathrm{~A} \rightarrow \mathrm{C}$ & 0.0833 & 0.0939 \\
\hline
\end{tabular}

Finally, we performed a stepwise forward selection procedure to examine the effects of the genotypes of the polymorphisms associated with hypertension by multivariate logistic regression analysis, as well as the effects of age, gender and the prevalence of diabetes mellitus on hypertension (Table VI). Diabetes mellitus, the HSPA8 genotype (recessive model) and the THBS2 genotype (dominant model), in descending order of statistical significance, were significant $(\mathrm{P}<0.05)$ and independent determinants of hypertension in individuals with CKD.

\section{Discussion}

We examined the possible relations of 50 polymorphisms in 46 candidate genes to the prevalence of hypertension in 1824 Japanese individuals with CKD. Our association study revealed that the $3949 \mathrm{~T} \rightarrow \mathrm{G}\left(3^{\prime}-\mathrm{UTR}\right)$ polymorphism of THBS 2 and the $-110 \mathrm{~A} \rightarrow \mathrm{C}$ polymorphism of HSPA8 were significantly associated with the prevalence of hypertension in such individuals.

Thrombospondin 2 (THBS2), a member of the thrombospondin family, is an extracellular matrix glycoprotein (13) that plays an important role in cell adhesion, migration and proliferation, as well as in angiogenesis. It is also implicated in atherosclerosis and thrombosis due to its function in the regulation of matrix metallopeptidase 2 (MMP2), a potential determinant of plaque vulnerability $(14,15)$. THBS2-deficient fibroblasts were shown to produce twice as much MMP2 as wild-type cells (16). However, THBS2 has not been detected in human plasma (17). The 3949T $\rightarrow \mathrm{G}\left(3^{\prime}-\mathrm{UTR}\right)$ polymorphism of THBS2 was previously shown to be associated with myo-

Table V. Multivariable logistic regression analysis of polymorphisms associated (FDR <0.5) with hypertension by the $\chi^{2}$ test for individuals with chronic kidney disease.

\begin{tabular}{|c|c|c|c|c|c|c|c|c|c|}
\hline \multirow{2}{*}{$\begin{array}{l}\text { Gene } \\
\text { symbol }\end{array}$} & \multirow[b]{2}{*}{ Polymorphism } & \multicolumn{2}{|c|}{ Dominant } & \multicolumn{2}{|c|}{ Recessive } & \multicolumn{2}{|c|}{ Additive 1} & \multicolumn{2}{|c|}{ Additive 2} \\
\hline & & $\mathrm{P}$-value & OR $(95 \% \mathrm{CI})$ & P-value & OR $(95 \% \mathrm{CI})$ & P-value & OR $(95 \% \mathrm{CI})$ & $\mathrm{P}$-value & OR $(95 \% \mathrm{CI})$ \\
\hline THBS2 & 3949T $\rightarrow \mathrm{G}\left(3^{\prime}-\mathrm{UTR}\right)$ & 0.0154 & $1.41(1.07-1.88)$ & 0.0400 & $8.31(1.70-15.3)$ & 0.0543 & & 0.0361 & $8.68(1.77-15.71)$ \\
\hline HSPA8 & $-110 \mathrm{~A} \rightarrow \mathrm{C}$ & 0.0406 & $0.79(0.64-0.99)$ & 0.0093 & $0.72(0.57-0.93)$ & 0.2251 & & 0.0044 & $0.66(0.50-0.88)$ \\
\hline
\end{tabular}

OR, odds ratio; CI, confidence interval. Multivariable logistic regression analysis was performed with adjustment for age, gender and the prevalence of diabetes mellitus. 
Table VI. Effects of genotypes and other characteristics on hypertension in individuals with chronic kidney disease determined by a stepwise forward selection procedure $(\mathrm{P}<0.05)$.

\begin{tabular}{lrc}
\hline Variable & P-value & $\mathrm{R}^{2}$ \\
\hline Diabetes mellitus & $<0.0001$ & 0.0325 \\
HSPA8 $(C C$ versus $A A+A C)$ & 0.0146 & 0.0027 \\
THBS2 $(T G+G G$ versus $T T)$ & 0.0164 & 0.0025 \\
\hline
\end{tabular}

$\mathrm{R}^{2}$, contribution rate.

cardial infarction, with the $G$ allele being protective against this condition (17-20). However, this finding has not been consistently replicated (21). Although the genetic variation of THBS2 has been extensively studied in individuals with various diseases, as far as we are aware it has not previously been associated with hypertension. We have now demonstrated that the $3949 \mathrm{~T} \rightarrow \mathrm{G}\left(3^{\prime}-\mathrm{UTR}\right)$ polymorphism of $T H B S 2$ is significantly associated with the prevalence of hypertension in individuals with CKD, with the $G$ allele representing a risk factor for this condition. The risk allele thus differed between the previous studies of myocardial infarction (17-20) and the present study. Although the reason for this discrepancy is unclear, it is possible that this polymorphism is in linkage disequilibrium with other polymorphisms responsible for the development of hypertension in individuals with CKD.

The expression of heat shock proteins in cells is induced by a wide variety of mechanical or other environmental stresses, with these proteins playing important roles as molecular chaperones $(22,23)$. They are present in the circulation of healthy individuals as well as in patients with various diseases (24). Heat shock 70-kDa protein 8 (HSPA8) is a key member of this protein family that also functions as a cytokine to stimulate a pro-inflammatory response in human monocytes (25). Its expression was induced in atherosclerotic plaques and appeared to protect arterial smooth muscle cells against plaque toxicity in an experimental model (26). The plasma level of HSPA8 has been shown to be increased in association with various diseases $(27,28)$. Furthermore, vascular expression of HSPA8 was found to be up-regulated in individuals with atherosclerotic diseases, including hypertension and myocardial infarction, possibly as a cytoprotective response to endothelial injury $(29,30)$. The $-110 \mathrm{~A} \rightarrow \mathrm{C}$ polymorphism of HSPA8 has been shown to influence gene function (31), while the variant $C$ allele of this polymorphism manifested lower transcriptional activity than the $A$ allele (32). We now demonstrated that the $-110 \mathrm{~A} \rightarrow \mathrm{C}$ polymorphism of HSPA8 is significantly associated with hypertension in individuals with CKD, with the $C$ allele being protective against this condition. The mechanism by which a reduced transcriptional activity of HSPA 8 might protect against hypertension in individuals with CKD remains unclear.

The present study has several limitations: (i) we used eGFR rather than directly measuring GFR to define CKD; (ii) we were unable to obtain information regarding underlying renal disease in the subjects with CKD (such information can be obtained by detailed clinical examination, including renal biopsy, but these diagnostic procedures are not considered feasible in a study whose subjects are recruited from the general population); (iii) it is possible that one or more of the polymorphisms associated with hypertension in the present study are in linkage disequilibrium with other polymorphisms in the same gene or in nearby genes that are actually responsible for the development of this condition; and (iv) the functional relevance of the association of the identified polymorphisms with hypertension was not examined.

In conclusion, our present results suggest that THBS2 and HSPA8 are susceptibility loci for hypertension in Japanese individuals with CKD. The determination of genotypes for the polymorphisms of these genes may prove informative for the assessment of the genetic risk of hypertension in individuals with CKD. Validation of our findings will require their replication with independent subject panels.

\section{Acknowledgements}

In addition to the authors, the following investigators participated in the study: H. Matsuo and T. Segawa (Gifu Prefectural General Medical Center); T. Hibino, K. Yajima, T. Fujimaki and T. Kawamiya (Gifu Prefectural Tajimi Hospital); T. Yoshida (Inabe General Hospital); and A. Yasunaga, H. Park, N. Fuku, M. Tanaka and T. Suzuki (Tokyo Metropolitan Institute of Gerontology). We also thank the nursing and laboratory staff of the participating hospitals. This work was supported in part by Grants-in-Aid for Scientific Research from the Ministry of Education, Culture, Sports, Science, and Technology of Japan (nos. 18209023, 18018021 and 19659149 to Y.Y.).

\section{References}

1. Buckalew VM Jr, Berg RL, Wang SR, Porush JG, Rauch S and Schulman G: Prevalence of hypertension in 1,795 subjects with chronic renal disease: the Modification of Diet in Renal Disease Study baseline cohort. Modification of Diet in Renal Disease Study Group. Am J Kidney Dis 28: 811-821, 1996.

2. Sarafidis PA, Li S, Chen SC, Collins AJ, Brown WW, Klag MJ and Bakris GL: Hypertension awareness, treatment, and control in chronic kidney disease. Am J Med 121: 332-340, 2008.

3. Coresh J, Selvin E, Stevens LA, Manzi J, Kusek JW, Eggers P, Van Lente F and Levey AS: Prevalence of chronic kidney disease in the United States. JAMA 298: 2038-2047, 2007.

4. Go AS, Chertow GM, Fan D, McCulloch CE and Hsu CY: Chronic kidney disease and the risks of death, cardiovascular events, and hospitalization. N Engl J Med 351: 1296-1305, 2004.

5. Sarnak MJ, Levey AS, Schoolwerth AC, Coresh J, Culleton B, Hamm LL, McCullough PA, Kasiske BL, Kelepouris E, Klag MJ, Parfrey P, Pfeffer M, Raij L, Spinosa DJ and Wilson PW; American Heart Association Councils on Kidney in Cardiovascular Disease, High Blood Pressure Research, Clinical Cardiology, and Epidemiology and Prevention: Kidney disease as a risk factor for development of cardiovascular disease: a statement from the American Heart Association Councils on Kidney in Cardiovascular Disease, High Blood Pressure Research, Clinical Cardiology, and Epidemiology and Prevention. Circulation 108: 2154-2169, 2003.

6. Yamagata K, Ishida K, Sairenchi T, Takahashi H, Ohba S, Shiigai T, Narita M and Koyama A: Risk factors for chronic kidney disease in a community-based population: a 10-year follow-up study. Kidney Int 71: 159-166, 2007.

7. Klag MJ, Whelton PK, Randall BL, Neaton JD, Brancati FL, Ford CE, Shulman NB and Stamler J: Blood pressure and endstage renal disease in men. N Engl J Med 334: 13-18, 1996.

8. Peterson JC, Adler S, Burkart JM, Greene T, Hebert LA, Hunsicker LG, King AJ, Klahr S, Massry SG and Seifter JL: Blood pressure control, proteinuria, and the progression of renal disease. The Modification of Diet in Renal Disease Study. Ann Intern Med 123: 754-762, 1995. 
9. National Kidney Foundation: K/DOQI clinical practice guidelines for chronic kidney disease: evaluation, classification, and stratification. Am J Kidney Dis 39 (2 suppl 1): 1-266, 2002.

10. Perloff D, Grim C, Flack J, Frohlich ED, Hill M, McDonald M and Morgenstern BZ: Human blood pressure determination by sphygmomanometry. Circulation 88: 2460-2470, 1993.

11. Itoh Y, Mizuki N, Shimada T, Azuma F, Itakura M, Kashiwase K, Kikkawa E, Kulski JK, Satake M and Inoko H: High-throughput DNA typing of HLA-A, -B, -C, and -DRB1 loci by a PCR-SSOPluminex method in the Japanese population. Immunogenetics 57 : 717-729, 2005

12. Benjamini Y and Hochberg Y: Controlling the false discovery rate: a practical and powerful approach to multiple testing. J Royal Stat Soc Ser B 57: 289-300, 1995

13. Laherty CD, O'Rourke K, Wolf FW, Katz R, Seldin MF and Dixit VM: Characterization of mouse thrombospondin 2 sequence and expression during cell growth and development. J Biol Chem 267: 3274-3281, 1992

14. Schroen B, Heymans S, Sharma U, Blankesteijn WM, Pokharel S, Cleutjens JP, Porter JG, Evelo CT, Duisters R, van Leeuwen RE, Janssen BJ, Debets JJ, Smits JF, Daemen MJ, Crijns HJ, Bornstein P and Pinto YM: Thrombospondin-2 is essential for myocardial matrix integrity: increased expression identifies failure-prone cardiac hypertrophy. Circ Res 95: 515-522, 2004.

15. Daniel C, Amann K, Hohenstein B, Bornstein P and Hugo C: Thrombospondin 2 functions as an endogenous regulator of angiogenesis and inflammation in experimental glomerulonephritis in mice. J Am Soc Nephrol 18: 788-798, 2007.

16. Yang Z, Kyriakides TR and Bornstein P: Matricellular proteins as modulators of cell-matrix interactions: adhesive defect in thrombospondin 2-null fibroblasts is a consequence of increased levels of matrix metalloproteinase-2. Mol Biol Cell 11: 3353-3364, 2000 .

17. Boekholdt SM, Trip MD, Peters RJ, Engelen M, Boer JM, Feskens EJ, Zwinderman AH, Kastelein JJ and Reitsma PH: Thrombospondin-2 polymorphism is associated with a reduced risk of premature myocardial infarction. Arterioscler Thromb Vasc Biol 22: 24-27, 2002.

18. Topol EJ, McCarthy J, Gabriel S, Moliterno DJ, Rogers WJ Newby LK, Freedman M, Metivier J, Cannata R, O'Donnell CJ, Kottke-Marchant K, Murugesan G, Plow EF, Stenina O and Daley GQ: Single nucleotide polymorphisms in multiple novel thrombospondin genes may be associated with familial premature myocardial infarction. Circulation 104: 2641-2644, 2001

19. McCarthy JJ, Parker A, Salem R, Moliterno DJ, Wang Q, Plow EF, Rao S, Shen G, Rogers WJ, Newby LK, Cannata R, Glatt K and Topol EJ; GeneQuest Investigators: Large scale association analysis for identification of genes underlying premature coronary heart disease: cumulative perspective from analysis of 111 candidate genes. J Med Genet 41: 334-341, 2004.
20. Morgan TM, Krumholz HM, Lifton RP and Spertus JA: Nonvalidation of reported genetic risk factors for acute coronary syndrome in a large-scale replication study. JAMA 297: 1551-1561, 2007.

21. Koch W, Hoppmann P, de Waha A, Schömig A and Kastrati A: Polymorphisms in thrombospondin genes and myocardial infarction: a case-control study and a meta-analysis of available evidence. Hum Mol Genet 17: 1120-1126, 2008.

22. Li Z, Menoret A and Srivastava P: Roles of heat-shock proteins in antigen presentation and cross-presentation. Curr Opin Immunol 14: 45-51, 2002.

23. Polla BS: A role for heat shock proteins in inflammation? Immunol Today 9: 134-137, 1998.

24. Dhingra R, Larson MG, Benjamin EJ, Lipinska I, Gona P, Corey D, Keaney JF Jr and Vasan RS: Cross-sectional correlates of serum heat shock protein 70 in the community. Am J Hypertens 19: 227-231, 2006.

25. Asea A, Kraeft SK, Kurt-Jones EA, Stevenson MA, Chen LB Finberg RW, Koo GC and Calderwood SK: HSP70 stimulates cytokine production through a CD14-dependent pathway, demonstrating its dual role as a chaperone and cytokine. Nat Med 6: 435-442, 2000

26. Johnson AD, Berberian PA, Tytell M and Bond MG: Differential distribution of $70-\mathrm{kD}$ heat shock protein in atherosclerosis. Its potential role in arterial SMC survival. Arterioscler Thromb Vasc Biol 15: 27-36, 1995.

27. Vignola AM, Chanez P, Polla BS, Vic P, Godard P and Bousquet $\mathrm{J}$ : Increased expression of heat shock protein 70 on airway cells in asthma and chronic bronchitis. Am J Respir Cell Mol Biol 13: 683-691, 1995.

28. Madách K, Molvarec A, Rigó J Jr, Nagy B, Pénzes I, Karádi I and Prohászka Z: Elevated serum $70 \mathrm{kDa}$ heat shock protein level reflects tissue damage and disease severity in the syndrome of hemolysis, elevated liver enzymes, and low platelet count. Eur J Obstet Gynecol Reprod Biol 139: 133-138, 2008.

29. Dybdahl B, Slørdahl SA, Waage A, Kierulf P, Espevik T and Sundan A: Myocardial ischaemia and the inflammatory response: release of heat shock protein 70 after myocardial infarction. Heart 91: 299-304, 2005.

30. Timofeeva AV, Goryunova LE, Khaspekov GL, Kovalevskii DA, Scamrov AV, Bulkina OS, Karpov YA, Talitskii KA, Buza VV, Britareva VV and Beabealashvilli RSH: Altered gene expression pattern in peripheral blood leukocytes from patients with arterial hypertension. Ann NY Acad Sci 1091: 319-335, 2006.

31. Cascino I, Sorrentino R and Tosi R: Strong genetic association between HLA-DR3 and a polymorphic variation in the regulatory region of the HSP70-1 gene. Immunogenetics 37: 177-182, 1993.

32. Wu YR, Wang CK, Chen CM, Hsu Y, Lin SJ, Lin YY, Fung HC, Chang KH and Lee-Chen GJ: Analysis of heat-shock protein 70 gene polymorphisms and the risk of Parkinson's disease. Hum Genet 114: 236-241, 2004. 